\title{
ESTRATIFICAÇÃO AMBIENTAL PARA AVALIAÇÃO E RECOMENDAÇÃO DE VARIEDADES DE MILHO NO ESTADO DE GOIÁS ${ }^{1}$
}

\author{
Cristiane Rachel de Paiva Felipe 2 , João Batista Duarte ${ }^{3}$, Luciene Fróes Camarano ${ }^{4}$
}

\section{ABSTRACT \\ ENVIRONMENTAL STRATIFICATION FOR MAIZE \\ VARIETIES EVALUATION AND RECOMMENDATION IN GOIÁS STATE, BRAZIL}

The objective of this study was to identify environmental strata for maize varieties recommendation and key locations for this kind of trial in Goiás State, Brazil. Forty-seven trials from the maize varieties evaluation program, carried out at Secretaria da Agricultura, Pecuária e Abastecimento do Estado de Goiás (Seagro-GO), over four growing seasons (2002/2003, 2003/2004, $2004 / 2005$, and 2005/2006) were evaluated. The environmental stratification was performed by using the winner genotypes AMMI approach, which allows, due to the study of genotypes by environment interactions (GxE), the identification of the genotypes most adapted to each environment, as well as the constitution of similar environmental location groups. Two environmental strata showed stability throughout the evaluated growing seasons, mainly for the group formed by the locations of Ipameri, Inhumas and Senador Canêdo, stable along the four years, and the one composed by Porangatu and Orizona, stable throughout three growing years. From that, it is possible to reduce at least $16 \%$ of the currently used test locations and/or replace them by other locations, aiming to increase the efficiency of the varietal evaluation in that region. The ALBandeirante cultivar showed high yield potential and adaptability to the maize crop conditions in Goiás.

KEY-WORDS: AMMI analysis; winner genotypes; GxE interaction; adaptability; zoning.

\section{INTRODUÇÃO}

Redes de avaliação de cultivares são partes imprescindíveis nos programas de melhoramento de plantas. Com sua realização, pode ser estudado o comportamento dos genótipos desenvolvidos em ampla faixa de condições ambientais, objetivando identificar os materiais genéticos mais promissores

\section{RESUMO}

O objetivo deste estudo foi identificar estratos ambientais para a recomendação de variedades de milho e locais-chave para a condução de ensaios deste tipo, em Goiás. Foram avaliados 47 ensaios, em quatro safras (2002/2003, 2003/2004, 2004/2005 e 2005/2006) do programa de avaliação de variedades de milho da Secretaria da Agricultura, Pecuária e Abastecimento do Estado de Goiás (Seagro-GO). A estratificação ambiental foi implementada por meio da abordagem AMMI de genótipos vencedores, que permite, pelo estudo da interação de genótipos com ambientes (GxA), tanto a identificação dos genótipos mais adaptados a cada ambiente quanto a formação de grupos de ambientes similares. Foram estabelecidos dois estratos ambientais, que se mostraram consistentes ao longo das safras agrícolas avaliadas, com destaque para os agrupamentos de Ipameri, Inhumas e Senador Canêdo, estáveis ao longo de quatro anos, e Porangatu e Orizona, estáveis por três anos. Com a estratificação obtida, é possível redução de, pelo menos, $16 \%$ dos locais de teste atualmente utilizados e/ou sua substituição por outros locais, buscando-se aumentar a eficiência da avaliação varietal na região. A variedade ALBandeirante apresentou alto potencial produtivo e grande adaptabilidade às condições de cultivo do milho em Goiás.

PALAVRAS-CHAVE: Análise AMMI; genótipos vencedores; interação GxA; adaptabilidade; zoneamento.

para as diversas condições avaliadas. Isto acontece graças à possibilidade de se analisar a interação dos genótipos com os ambientes (GxA) que, ao ser identificada, pode ser revertida em favor da maximização das produtividades da cultura.

Dessa forma, o melhoramento pode voltar-se para a exploração de genótipos de ampla adaptabilidade, oferecendo ao setor produtivo cultivares

1. Trabalho recebido em maio/2009 e aceito para publicação em jun./2010 (nº registro: PAT 6158/ DOI: 10.5216/pat.v40i2.6158).

2. Secretaria da Agricultura, Pecuária e Abastecimento do Estado de Goiás (Seagro-GO), Estação Experimental de

Senador Canêdo, Senador Canêdo, GO, Brasil.E-mail: cristianerachel@yahoo.com.br.

3. Universidade Federal de Goiás, Escola de Agronomia e Engenharia de Alimentos, Setor de Genética e

Melhoramento de Plantas, Goiânia, GO, Brasil.E-mail: jbduarte@agro.ufg.br.

4. Centro Universitário de Goiás Uni-Anhanguera, Núcleo de Ciências Exatas e Biológicas, Goiânia, GO, Brasil.

E-mail: lucienecamarano@yahoo.com.br. 
que se sobressaiam em ampla faixa ambiental e/ou cultivares adaptadas a condições específicas, que podem ser adversas ou extremamente favoráveis. $\mathrm{O}$ Programa Milho, da Secretaria da Agricultura, Pecuária e Abastecimento do Estado de Goiás (SeagroGO)/Agência Goiana de Desenvolvimento Rural e Fundiário (AgênciaRural - Goiás), tem avaliado cultivares comerciais e pré-comerciais, em parceria com empresas privadas e instituições de ensino e pesquisa de todo o Brasil. Sua rede de ensaios cobre, usualmente, uma faixa superior a dez ambientes por safra, buscando avaliar locais que sejam divergentes e tenham aptidão para a produção de milho.

A estratificação de uma região, ou seja, a sua subdivisão em zonas relativamente homogêneas (estratos), permite, além da identificação e recomendação de genótipos superiores em cada estrato, a eliminação de locais de teste redundantes, na rede de ensaios. Com efeito, o programa de melhoramento passa a ter uma melhor alocação de recursos materiais e técnicos e maior possibilidade de sucesso na identificação dos genótipos, pela utilização de locais mais divergentes. Com a economia de pontos de teste, o programa pode investir no aumento do número de genótipos a serem avaliados ou na inclusão de novos locais de teste, que possam trazer mais informações à avaliação da interação GxA.

Por mais que o conhecimento e a utilização de informações sobre fatores ambientais associados à produção vegetal sejam importantes, Gauch (1992) afirma que as avaliações de similaridade ambiental, com base nos efeitos da interação GxA, são mais confiáveis que aquelas baseadas apenas nestes fatores, sem considerar-se os seus impactos sobre a interação GxA. Entre os métodos utilizados para este fim, o uso da "abordagem dos genótipos vencedores", associada à análise AMMI (additive main effects and multiplicative interaction), descrita por Gauch (1992) e Gauch \& Zobel (1997), tem permitido a construção de estratos ambientais estáveis, ao longo dos anos, para diferentes culturas e regiões (Ebdon \& Gauch 2002, Maranha 2005, Pacheco et al. 2009).

Apesar de existirem outros métodos para este tipo de estudo, como, por exemplo, a técnica GGE biplot (genotype main effects and genotype $x$ environment interaction), fortemente defendida em artigos recentes (Yan \& Tinker 2005, Yan et al. 2007, Balestre et al. 2009), Gauch (2006) aponta a abordagem AMMI como ideal para esta finalidade, por separar os efeitos de genótipos, ambientes e interação
GxA, antes da aplicação da Decomposição de Valores Singulares (DVS), o que pode ser feito em qualquer conjunto de dados. Gauch et al. (2008) elucidam outras diferenças entre os dois procedimentos. O método GGE, por outro lado, separa o efeito do ambiente, antes da aplicação da DVS, e, só então, tenta separar o efeito de G e GxA, o que depende de propriedades especiais da base de dados, que, nem sempre, estão presentes. Ademais, Miranda et al. (2009) afirmam que, quando a interação GxA é bem capturada pelo primeiro componente principal AMMI, os gráficos resultantes desta abordagem descrevem as respostas adaptativas dos genótipos de forma mais simples e clara.

O objetivo deste trabalho foi realizar uma estratificação ambiental para recomendação de variedades de milho em Goiás, baseada na abordagem dos genótipos vencedores e associada à análise AMMI, buscando-se a indicação de zonas agronômicas ou mega-ambientes estáveis, através dos anos agrícolas.

\section{MATERIAL E MÉTODOS}

Foram utilizados dados de produtividade de grãos $\left(\mathrm{kg} \mathrm{ha}^{-1}\right)$ provenientes de 47 experimentos da rede de ensaios regionais de avaliação de variedades de milho, conduzidos pela Seagro-GO/AgênciaRuralGoiás, em parceria com a Fundação de Desenvolvimento e Assistência Técnica e Extensão Rural de Goiás (Fundater). Os ensaios foram conduzidos durante quatro safras de verão, 2002/2003, 2003/2004, 2004/2005 e 2005/2006 (Tabelas 1 e 2), totalizando 19 locais. Ao longo de todo o período, foram avaliados 41 genótipos, incluindo, principalmente, variedades de polinização aberta e alguns híbridos experimentais e comerciais (Tabela 3 ).

Nos experimentos, foi utilizado o delineamento em látice, com as seguintes variações: látice 5x3, com 15 tratamentos, em 2002/2003; látice 6x4, com 24 tratamentos, em 2003/2004; látice $7 \times 4$, com 28 tratamentos, em 2004/2005; e látice 6x3, com 18 tratamentos, em 2005/2006. Os tratamentos (variedades e híbridos) variaram de um ano para outro, como resultado da substituição natural de genótipos em programas de melhoramento genético de plantas. Cada parcela consistiu de duas linhas de plantas, com variações de um experimento para outro, de 4,0 $\mathrm{m}$ a 5,0 $\mathrm{m}$ de comprimento e espaçamentos de $0,4 \mathrm{~m}$ a $1,0 \mathrm{~m}$ nas entrelinhas. Por este motivo, os 
Tabela 1. Localidades, suas coordenadas geográficas e datas de plantio dos ensaios de competição de variedades de milho da Secretaria da Agricultura, Pecuária e Abastecimento do Estado de Goiás, nas safras 2002/2003 e 2003/2004, em Goiás.

\begin{tabular}{lccccccc}
\hline \multicolumn{1}{c}{ Localidade } & $\begin{array}{c}\text { Latitude } \\
\text { Sul }\end{array}$ & $\begin{array}{c}\text { Longitude } \\
\text { Oeste }^{1}\end{array}$ & $\begin{array}{c}\text { Altitude } \\
(\mathrm{m})\end{array}$ & $\begin{array}{c}\text { Safra } \\
2002 / 2003\end{array}$ & $\begin{array}{c}\text { Data } \\
\text { de Plantio }\end{array}$ & $\begin{array}{c}\text { Safra } \\
2003 / 2004\end{array}$ & $\begin{array}{c}\text { Data } \\
\text { de Plantio }\end{array}$ \\
\hline Campo Alegre & $17^{\circ} 41^{\prime} 15^{\prime \prime}$ & $47^{\circ} 48^{\prime} 55^{\prime \prime}$ & 920 & - & - & $\mathrm{x}$ & $22 / 11 / 2003$ \\
Goianésia & $15^{\circ} 18^{\prime} 45^{\prime \prime}$ & $49^{\circ} 03^{\prime} 45^{\prime \prime}$ & 670 & $\mathrm{x}^{2}$ & $26 / 11 / 2002$ & $\mathrm{x}$ & $12 / 11 / 2003$ \\
Goiatuba & $18^{\circ} 03^{\prime} 45^{\prime \prime}$ & $49^{\circ} 18^{\prime} 45^{\prime \prime}$ & 580 & $\mathrm{x}$ & $07 / 12 / 2002$ & - & - \\
Inhumas & $16^{\circ} 18^{\prime} 45^{\prime \prime}$ & $49^{\circ} 26^{\prime} 15^{\prime \prime}$ & 800 & $\mathrm{x}$ & $13 / 11 / 2002$ & $\mathrm{x}$ & $10 / 11 / 2003$ \\
Ipameri & $17^{\circ} 41^{\prime} 15^{\prime \prime}$ & $48^{\circ} 11^{\prime} 15^{\prime \prime}$ & 800 & $\mathrm{x}$ & - & $\mathrm{x}$ & $10 / 11 / 2003$ \\
Itaberaí & $16^{\circ} 03^{\prime} 45^{\prime \prime}$ & $49^{\circ} 48^{\prime} 45^{\prime \prime}$ & 640 & - & - & $\mathrm{x}$ & $01 / 12 / 2003$ \\
Itumbiara & $18^{\circ} 26^{\prime} 15^{\prime \prime}$ & $49^{\circ} 11^{\prime} 15^{\prime \prime}$ & 420 & - & - & $\mathrm{x}$ & $02 / 12 / 2003$ \\
Morrinhos & $17^{\circ} 41^{\prime} 15^{\prime \prime}$ & $49^{\circ} 03^{\prime} 45^{\prime \prime}$ & 830 & $\mathrm{x}$ & $27 / 11 / 2002$ & $\mathrm{x}$ & $05 / 11 / 2003$ \\
Orizona & $17^{\circ} 03^{\prime} 45^{\prime \prime}$ & $48^{\circ} 18^{\prime} 45^{\prime \prime}$ & 910 & - & - & $\mathrm{x}$ & $31 / 10 / 2003$ \\
Palmeiras & $16^{\circ} 48^{\prime} 45^{\prime \prime}$ & $49^{\circ} 56^{\prime} 15^{\prime \prime}$ & 560 & $\mathrm{x}$ & $08 / 11 / 2002$ & - & - \\
Porangatu & $13^{\circ} 26^{\prime} 15^{\prime \prime}$ & $49^{\circ} 11^{\prime} 15^{\prime \prime}$ & 620 & $\mathrm{x}$ & $20 / 11 / 2002$ & $\mathrm{x}$ & $18 / 11 / 2003$ \\
Rio Verde & $17^{\circ} 48^{\prime} 45^{\prime \prime}$ & $50^{\circ} 56^{\prime} 15^{\prime \prime}$ & 745 & - & - & $\mathrm{x}$ & $14 / 11 / 2003$ \\
Senador Canêdo & $16^{\circ} 41^{\prime} 15^{\prime \prime}$ & $49^{\circ} 03^{\prime} 45^{\prime \prime}$ & 741 & $\mathrm{x}$ & $07 / 11 / 2002$ & $\mathrm{x}$ & $04 / 11 / 2003$ \\
Senador Canêdo 2 & $16^{\circ} 41^{\prime} 15^{\prime \prime}$ & $49^{\circ} 03^{\prime} 45^{\prime \prime}$ & 741 & $\mathrm{x}$ & $29 / 11 / 2002$ & - & - \\
\hline
\end{tabular}

${ }^{1}$ Coordenadas referentes aos pontos centrais das imagens (Miranda \& Coutinho 2004).

${ }^{2}$ A letra " $x$ " indica que o ensaio foi conduzido nos respectivos locais e safras.

Tabela 2. Localidades, suas coordenadas geográficas e datas de plantio dos ensaios de competição de variedades de milho da Secretaria da Agricultura, Pecuária e Abastecimento do Estado de Goiás, nas safras 2004/2005 e 2005/2006, em Goiás.

\begin{tabular}{|c|c|c|c|c|c|c|c|}
\hline Localidade & $\begin{array}{c}\text { Latitude } \\
\text { Sul }^{1}\end{array}$ & $\begin{array}{l}\text { Longitude } \\
\text { Oeste }^{1}\end{array}$ & $\begin{array}{l}\text { Altitude } \\
(\mathrm{m})\end{array}$ & $\begin{array}{c}\text { Safra } \\
2004 / 2005\end{array}$ & $\begin{array}{l}\text { Data de } \\
\text { Plantio }\end{array}$ & $\begin{array}{c}\text { Safra } \\
2005 / 2006\end{array}$ & $\begin{array}{l}\text { Data de } \\
\text { Plantio }\end{array}$ \\
\hline Bom Jesus & $18^{\circ} 11^{\prime} 15^{\prime \prime}$ & $49^{\circ} 41^{\prime} 15^{\prime \prime}$ & 619 & $\mathrm{X}$ & $5 / 11 / 2004$ & - & - \\
\hline Caiapônia & $16^{\circ} 56^{\prime} 15^{\prime \prime}$ & $51^{\circ} 48^{\prime} 45^{\prime \prime}$ & 750 & - & - & $\mathrm{X}$ & $11 / 11 / 2005$ \\
\hline Campo Alegre & $17^{\circ} 41^{\prime} 15^{\prime \prime}$ & $47^{\circ} 48^{\prime} 55^{\prime \prime}$ & 950 & $X^{2}$ & $25 / 11 / 2004$ & $\mathrm{X}$ & $05 / 11 / 2005$ \\
\hline Goianésia & $15^{\circ} 18^{\prime} 45^{\prime \prime}$ & $49^{\circ} 03^{\prime} 45^{\prime \prime}$ & 670 & $\mathrm{X}$ & $09 / 12 / 2004$ & $\mathrm{X}$ & $25 / 11 / 2005$ \\
\hline Goiatuba & $18^{\circ} 03^{\prime} 45^{\prime \prime}$ & $49^{\circ} 18^{\prime} 45^{\prime \prime}$ & 600 & $\mathrm{X}$ & $20 / 11 / 2004$ & $\mathrm{X}$ & $14 / 11 / 2005$ \\
\hline Hidrolândia & $16^{\circ} 56^{\prime} 15^{\prime \prime}$ & $49^{\circ} 11^{\prime} 15^{\prime \prime}$ & 775 & - & - & $\mathrm{X}$ & $10 / 11 / 2005$ \\
\hline Inhumas & $16^{\circ} 18^{\prime} 45^{\prime \prime}$ & $49^{\circ} 26^{\prime} 15^{\prime \prime}$ & 800 & $\mathrm{X}$ & $26 / 11 / 2004$ & $\mathrm{X}$ & $08 / 11 / 2005$ \\
\hline Ipameri & $17^{\circ} 41^{\prime} 15^{\prime \prime}$ & $48^{\circ} 11^{\prime} 15^{\prime \prime}$ & 800 & $\mathrm{X}$ & $02 / 12 / 2004$ & $\mathrm{X}$ & $25 / 11 / 2005$ \\
\hline Itaberaí & $16^{\circ} 03^{\prime} 45^{\prime \prime}$ & $49^{\circ} 48^{\prime} 45^{\prime \prime}$ & 640 & $\mathrm{X}$ & $10 / 11 / 2004$ & $\mathrm{X}$ & $16 / 11 / 2005$ \\
\hline Itumbiara & $18^{\circ} 26^{\prime} 15^{\prime \prime}$ & $49^{\circ} 11^{\prime} 15^{\prime \prime}$ & 420 & $\mathrm{X}$ & $15 / 11 / 2004$ & - & - \\
\hline Montes Claros & $16^{\circ} 03^{\prime} 45^{\prime \prime}$ & $51^{\circ} 26^{\prime} 15^{\prime \prime}$ & 472 & $\mathrm{X}$ & $09 / 11 / 2004$ & - & - \\
\hline Morrinhos & $17^{\circ} 41^{\prime} 15^{\prime \prime}$ & $49^{\circ} 03^{\prime} 45^{\prime \prime}$ & 771 & $\mathrm{X}$ & $03 / 12 / 2004$ & - & - \\
\hline Orizona & $17^{\circ} 03^{\prime} 45^{\prime \prime}$ & $48^{\circ} 18^{\prime} 45^{\prime \prime}$ & 910 & $\mathrm{X}$ & $30 / 10 / 2004$ & $\mathrm{X}$ & $04 / 11 / 2005$ \\
\hline Palmeiras & $16^{\circ} 48^{\prime} 45^{\prime \prime}$ & $49^{\circ} 56^{\prime} 15^{\prime \prime}$ & 560 & $\mathrm{X}$ & $29 / 10 / 2004$ & - & - \\
\hline Porangatu & $13^{\circ} 26^{\prime} 15^{\prime \prime}$ & $49^{\circ} 11^{\prime} 15^{\prime \prime}$ & 620 & $\mathrm{X}$ & $11 / 11 / 2004$ & $\mathrm{X}$ & $28 / 12 / 2005$ \\
\hline Rio Verde & $17^{\circ} 48^{\prime} 45^{\prime \prime}$ & $50^{\circ} 56^{\prime} 15^{\prime \prime}$ & 836 & $\mathrm{X}$ & $12 / 11 / 2004$ & $\mathrm{X}$ & $25 / 11 / 2005$ \\
\hline Senador Canêdo & $16^{\circ} 41^{\prime} 15^{\prime \prime}$ & $49^{\circ} 03^{\prime} 45^{\prime \prime}$ & 741 & $\mathrm{X}$ & $04 / 11 / 2004$ & $X$ & $03 / 12 / 2005$ \\
\hline
\end{tabular}

${ }^{1}$ Coordenadas referentes aos pontos centrais das imagens (Miranda \& Coutinho 2004).

${ }^{2}$ A letra " $x "$ indica que o ensaio foi conduzido naqueles respectivos locais e safras. 
Tabela 3. Genótipos testados nos ensaios da rede de avaliação de variedades de milho da Secretaria da Agricultura, Pecuária e Abastecimento do Estado de Goiás, empresa produtora e anos agrícolas em que foram avaliados.

\begin{tabular}{|c|c|c|c|c|c|c|c|c|c|c|c|c|c|}
\hline Genótipo & Tipo $^{1}$ & $\begin{array}{l}\text { Empresa } \\
\text { Produtora } \\
\end{array}$ & $\begin{array}{l}2002 / \\
2003 \\
\end{array}$ & 20 & $\begin{array}{l}2004 / \\
2005 \\
\end{array}$ & \begin{tabular}{|l|}
$2005 /$ \\
2006 \\
\end{tabular} & Genótipo & Tipo $^{1}$ & $\begin{array}{c}\text { Empresa } \\
\text { Produtora }\end{array}$ & $\begin{array}{l}2002 / \\
2003 \\
\end{array}$ & $\begin{array}{l}03 \\
04 \\
\end{array}$ & $2004 /$ & $\begin{array}{l}2005 / \\
2006 \\
\end{array}$ \\
\hline Airã & V & Cegran/IAC & $\mathrm{x}^{2}$ & & & & IAC8333 & $\mathrm{HV}$ & IAC & $\mathrm{x}$ & & $\mathrm{x}$ & \\
\hline AL200205 & V & Cati & & & & $\mathrm{x}$ & Ipiranga & V & Cati & & $\mathrm{x}$ & $\mathrm{x}$ & $\mathrm{x}$ \\
\hline AL25 & V & Cati & $\mathrm{x}$ & $\mathrm{x}$ & $\mathrm{x}$ & & IPR114 & V & Iapar & $\mathrm{x}$ & $\mathrm{x}$ & & $\mathrm{x}$ \\
\hline AL30 & V & Cati & $\mathrm{x}$ & $\mathrm{x}$ & $\mathrm{x}$ & & IPV7352 & V & Iapar & & & & $\mathrm{x}$ \\
\hline AL34 & V & Cati & $\mathrm{x}$ & $\mathrm{x}$ & $\mathrm{x}$ & $\mathrm{x}$ & Orion & $\mathrm{HM}$ & Phd Sementes & & & $\mathrm{x}$ & \\
\hline AlBandeirante & V & AgênciaRural & $\mathrm{l} x$ & $\mathrm{x}$ & $\mathrm{x}$ & $\mathrm{x}$ & PC0201 & V & Iapar & & & $\mathrm{x}$ & $\mathrm{x}$ \\
\hline AlBianco & V & Cati & & $\mathrm{x}$ & $\mathrm{x}$ & $\mathrm{x}$ & PC0202 & V & Iapar & & & $\mathrm{x}$ & \\
\hline Alvorada & V & Cati & & $\mathrm{x}$ & $\mathrm{x}$ & $\mathrm{x}$ & PC0203 & V & Iapar & & & $\mathrm{x}$ & \\
\hline AREgo18 & V & AgênciaRural & $1 x$ & & & & PC9703 & V & Iapar & $\mathrm{x}$ & & $\mathrm{x}$ & \\
\hline AsPreto & V & Embrapa & & $\mathrm{x}$ & $\mathrm{x}$ & $\mathrm{x}$ & PC9902 & V & Iapar & & $\mathrm{x}$ & & \\
\hline BR106 & V & AgênciaRural & & $\mathrm{x}$ & $\mathrm{x}$ & $\mathrm{x}$ & PC9903 & V & Iapar & & $\mathrm{x}$ & & \\
\hline BRS1010 & HS & Embrapa & & $\mathrm{x}$ & & & Piratininga & V & Cati & & $\mathrm{x}$ & $\mathrm{x}$ & $\mathrm{x}$ \\
\hline BRS2020 & HD & Embrapa & & & $\mathrm{x}$ & & Samambóleo & V & UFG & $\mathrm{x}$ & & & \\
\hline BRS4150 & V & Embrapa & & $\mathrm{x}$ & $\mathrm{x}$ & $\mathrm{x}$ & Samambaia & V & UFG & & $\mathrm{x}$ & $\mathrm{x}$ & $\mathrm{x}$ \\
\hline BRS473 & V & Embrapa & $\mathrm{x}$ & $\mathrm{x}$ & $\mathrm{x}$ & $\mathrm{x}$ & Saracura & V & Embrapa & $\mathrm{x}$ & & $\mathrm{x}$ & \\
\hline BRSCaimbé & V & Embrapa & & $\mathrm{x}$ & & & SHS3030 & V & S. Helena & $\mathrm{x}$ & & & \\
\hline Cativerde1 & V & Cati & & $\mathrm{x}$ & & & SHS3031 & V & S. Helena & & $\mathrm{x}$ & & \\
\hline Cativerde2 & V & Cati & & $\mathrm{x}$ & $\mathrm{x}$ & & Sol da manhã & V & Embrapa & $\mathrm{x}$ & $\mathrm{x}$ & $\mathrm{x}$ & $\mathrm{x}$ \\
\hline Cerrado & V & Embrapa & & & $\mathrm{x}$ & & UFVM100 & V & UFV & & & $\mathrm{x}$ & $\mathrm{x}$ \\
\hline Emca202 & V & Emcapa & $\mathrm{x}$ & $\mathrm{x}$ & $\mathrm{x}$ & & UFVM200 & V & UFV & & & $\mathrm{x}$ & $\mathrm{x}$ \\
\hline Emgopa501 & V & AgênciaRural & & $\mathrm{x}$ & $\mathrm{x}$ & & - & - & - & - & - & - & - \\
\hline
\end{tabular}

${ }^{1}$ V: variedade; HS: híbrido simples; HD: híbrido duplo; HM: híbrido duplo modificado; HV: híbrido intervarietal.

${ }^{2}$ A letra "x", nas colunas, indica a inclusão do genótipo na avaliação da respectiva safra.

dados de produção por parcela foram ajustados por análise de covariância, para uma população inicial de 60 mil plantas por hectare, conforme preconizam Vencovsky \& Barriga (1992).

Para a obtenção das médias genotípicas, nas análises individuais dos experimentos, foi adotado o seguinte modelo em delineamento de blocos incompletos-látice:

$$
\mathrm{Y}_{\mathrm{ij}}=\mu+\beta_{\mathrm{j}}+\tau_{\mathrm{i}}+\varepsilon_{\mathrm{ij}}
$$

em que $Y_{\mathrm{ijk}}$ é o valor observado para o tratamento ou genótipo $i$, no bloco $j ; \mu$ a média geral do experimento; $\tau_{i}$ o efeito do tratamento $i ; \beta_{j}$ o efeito do bloco $j$ (reunindo o efeito de bloco dentro da repetição do látice); e $\varepsilon_{\mathrm{ijk}} \mathrm{o}$ erro experimental associado à observação $\mathrm{Y}_{\mathrm{ij}}$. $\mathrm{O}$ modelo foi admitido como aleatório, em razão de estudo prévio (Felipe 2008), que resultou em maior acurácia e menor erro quadrático médio, para as predições de valor genotípico obtidas por esta abordagem analítica.
A homogeneidade de variâncias entre os experimentos foi avaliada, dentro de cada safra, pelo critério de Pimentel Gomes (1990), isto é, considerando-se a razão entre a maior e a menor variância do erro inferior a sete. Realizaram-se, então, as análises conjuntas de variância, por safra, de acordo com o modelo a seguir, também admitido como aleatório:

$$
\mathrm{Y}_{\mathrm{ijk}}=\mu+\alpha_{\mathrm{k}}+\beta_{\mathrm{j}(\mathrm{k})}+\tau_{\mathrm{i}}+(\tau \alpha)_{\mathrm{ik}}+\varepsilon_{\mathrm{ijk}}
$$

em que $\mathrm{Y}_{\mathrm{ijk}}$ é a média do tratamento i no bloco $\mathrm{j}$, dentro do local k; $\mu$ a média geral; $\alpha_{\mathrm{k}} \mathrm{o}$ efeito do local $\mathrm{k} ; \beta_{\mathrm{j}(\mathrm{k})}$ o efeito do bloco $\mathrm{j}$ (reunindo o efeito da repetição do látice), dentro do local $\mathrm{k} ; \tau_{\mathrm{i}} \mathrm{o}$ efeito do tratamento $\mathrm{i} ;(\tau \alpha)_{\mathrm{ij}}$ o efeito da interação do tratamento i com o local k; e $\varepsilon_{\mathrm{ijk}}$ o erro experimental associado à observação $\mathrm{Y}_{\mathrm{ijk}}$.

As predições das médias genotípicas foram executadas por meio do procedimento Proc Mixed (procedure for mixed models) do SAS ${ }^{\circledR}$, Statistical Analysis System (SAS Institute 2002). Utilizou-se 
o método REML (máxima verossimilhança restrita) para a estimação dos componentes de variância associados aos modelos. De posse das médias genotípicas preditas e dos respectivos quadrados médios residuais, para os diferentes ensaios, foram construídas matrizes com as médias dos genótipos por ambiente, dentro de cada safra, para se avaliar a interação de genótipos com ambientes (GxA). Esta avaliação foi implementada por análise AMMI (additive main effects and multiplicative interaction), uma abordagem de modelo fixo, cujo detalhamento e rotina computacional, em linguagem $\mathrm{SAS}^{\circledR}$, são descritos por Duarte \& Vencovsky (1999). A análise combina uma técnica univariada - análise de variância - para estimar os efeitos principais (genótipos e ambientes), assumidos como aditivos, e uma técnica multivariada - análise de componentes principais/decomposição por valores singulares - para estimar o padrão associado à interação GxA, assumida como efeito multiplicativo decorrente dos fatores nela envolvidos (Gauch 1992, Gauch \& Zobel 1996).

Em razão da falta das predições de média $\left(\mathrm{Y}_{\mathrm{ij}}\right)$ das cultivares ALBandeirante e BRS473, respectivamente, em Montes Claros, safra 2004/2005, e Porangatu, safra 2005/2006, e pelo fato de a análise AMMI mais difundida não admitir dados perdidos na matriz de médias, estas foram estimadas, dentro de cada safra, por

$$
Y_{i j}=\bar{Y}_{i .}+\bar{Y}_{. j}-\bar{Y}_{.}
$$

em que $\bar{Y}_{i}$ é a média do genótipo i sobre todos os locais; $\bar{Y}_{\mathrm{j}}$ a média do local j sobre todos os genótipos; $\mathrm{e} \overline{\mathrm{Y}}$.. a média geral dos experimentos.

A estratificação dos ambientes foi estabelecida por meio da abordagem de genótipos vencedores, conforme preconizam Gauch \& Zobel (1997) e Ebdon \& Gauch (2002). Define-se um genótipo vencedor como aquele que alcança a mais alta produtividade em dado ambiente (Gauch 1992, Gauch \& Zobel 1997). As estimativas AMMI1 (modelo que considera apenas o primeiro componente principal da interação) da produtividade de cada genótipo, em cada ambiente $\left(\widetilde{\mathrm{Y}}_{\mathrm{ij}}\right)$, foram obtidas por meio da equação

$$
\tilde{\mathrm{Y}}_{\mathrm{ij}}=\overline{\mathrm{Y}}_{\mathrm{i} .}+\left(\operatorname{IPCA} l_{i}\right)\left(\operatorname{IPCA} l_{j}\right)
$$

em que $\bar{Y}_{i}$ é a média do genótipo i sobre todos os ambientes; IPCA $l_{i}$ o escore do genótipo i no primeiro eixo principal de interação (IPCAl), estimado na análise de componentes principais; e IPCA $l_{\mathrm{j}}$ o es- core do ambiente $\mathrm{j}$, neste mesmo eixo de interação (IPCAl).

Dessa forma, a produtividade de cada genótipo, em cada ambiente $\left(\tilde{\mathrm{Y}}_{\mathrm{ij}}\right)$, pode ser representada como uma função linear simples do escore ambiental (IPCA $l_{j}$ ), isto é, uma equação da reta com intercepto $\bar{Y}_{i .}$ e inclinação igual ao escore genotípico de interação (IPCA $l_{i}$ ). O ponto de cruzamento entre duas destas retas, referentes a dois genótipos vencedores, define, portanto, a transição adaptativa dos dois genótipos e, ao mesmo tempo, dois estratos ambientais de adaptação produtiva. Estes genótipos apresentam adaptação específica ao estrato que os elegeu como vencedores e, simultaneamente, estabilidade, no sentido agronômico, para as localidades que compõem este estrato. Assim, um estrato caracteriza-se como um mega-ambiente - conjunto de locais que apresenta um vencedor comum. O ponto de cruzamento equivale, também, ao escore de ambiente em que a diferença entre as estimativas $\widetilde{Y}_{\mathrm{ij}}$ dos dois genótipos vencedores é igual à zero (Pacheco 2004). Estas análises foram implementadas em planilhas eletrônicas, construídas no aplicativo Microsoft Excel ${ }^{\circledR}$, que, também, foi utilizado para a geração dos respectivos gráficos.

Nos estratos cuja formação foi determinada por genótipos vencedores do tipo híbrido simples ou duplo, a recomendação de variedades e a estratificação ambiental foram feitas baseando-se no comportamento da primeira variedade vencedora, após a exclusão de tais híbridos. Além disso, conforme possibilita o método (Gauch 1996, Gauch \& Zobel 1997, Pacheco 2004), foram utilizados os artifícios de remoção de vencedores absolutos (genótipos com vitórias em todos os locais), para se avaliar, também, as adaptações específicas de outros materiais promissores, bem como a eliminação de vencedores menores (genótipos com vitórias em apenas um local), para se evitar recomendações muito particulares, fruto da estratificação excessiva da região.

\section{RESULTADOS E DISCUSSÃO}

De forma geral, as estimativas do coeficiente de variação experimental (CV) e das médias de produtividade de grãos, nos 47 ensaios analisados, foram aceitáveis e condizentes com experimentos de avaliação de cultivares, isto é, com os requisitos dos ensaios de VCU (valor de cultivo e uso) para a cultura do milho, estabelecidos pelo Ministério da Agricultura, Pecuária e Abastecimento (Brasil 1998). 
Os valores de CV variaram entre 5,6\% e 18,2\%, enquanto as médias de produtividade ficaram entre $3.564 \mathrm{~kg} \mathrm{ha}^{-1}$ e $9.207 \mathrm{~kg} \mathrm{ha}^{-1}$ (Figura 1).

Em relação à significância das interações dos genótipos com os ambientes (GxA), foram obtidos os seguintes $p$-valores: 0,2334 , em 2002/2003; 0,016, em 2003/2004; <0,001, em 2004/2005; e 0,0091, em $2005 / 2006$. Apesar de não ter sido constatada interação GxA significativa $(\alpha=0,05)$, na safra 2002/2003, as médias genotípicas preditas nos ambientes daquele ano agrícola também foram submetidas à análise AMMI. Isto, porque, segundo Gauch \& Zobel (1996), um estudo pormenorizado da fonte de variação GxA é justificável, mesmo em situações em que o teste de $F$ não aponte significância para o quadrado médio da interação GxA, pois, mesmo nestes casos, a análise AMMI, geralmente, possibilita a eliminação de ruído adicional, melhorando as predições das respostas fenotípicas dos genótipos.

Para a estratificação ambiental na safra 2002/2003, foram identificados, inicialmente, três genótipos vencedores: ALBandeirante, IAC8333 e PC9703 (Tabela 4). Os dois primeiros, juntos, venceram em oito dos nove locais, enquanto o último venceu em apenas um local (Senador Canêdo2), caracterizando-se como um vencedor menor (Figura 2a). Com a adoção do critério de eliminação de "vencedores menores" (Gauch 1996, Pacheco 2004), o genótipo PC9703 foi, então, excluído, no processo de definição dos estratos. Entre os vencedo- res principais, o de melhor desempenho, neste local, foi o IAC8333, que venceu em outros cinco locais. A extensão da área de adaptação deste genótipo, para a localidade de Senador Canêdo2, via exlcusão de vencedores menores (PC9703, Emcapa 202, AL 25 e AL 30), possibilitou a formação de um estrato mais amplo, sem grande prejuízo $\left(100 \mathrm{~kg} \mathrm{ha}^{-1}\right)$ à produtividade esperada no respectivo local. Sendo assim, a cultivar IAC 8333 determinou a formação de um estrato composto por Senador Canêdo2, Ipameri, Goiatuba, Inhumas, Morrinhos e Senador Canêdo, enquanto a variedade ALBandeirante determinou o estrato constituído por Goianésia, Porangatu e Palmeiras (Figura 2a).

O genótipo IAC8333, embora não seja variedade de polinização aberta, foi mantido para a constituição destes estratos ambientais, em razão de tratar-se de híbrido intervarietal. Para este tipo de cultivar, não se espera comportamento muito desviante daquele de variedades, como se esperaria, por exemplo, para o caso de híbridos de linhagens.

Na safra 2003/2004, a princípio, foi observada a formação de estrato ambiental único, que teve como genótipo vencedor a cultivar BRS1010 (Tabela 5). Tal cultivar, contudo, também não é variedade, mas sim híbrido simples. Por esta razão, foi desconsiderada para o propósito da estratificação ambiental buscada neste estudo. Com a exclusão deste híbrido, a variedade ALBandeirante revelou-se o genótipo vencedor em, praticamente, todos os locais

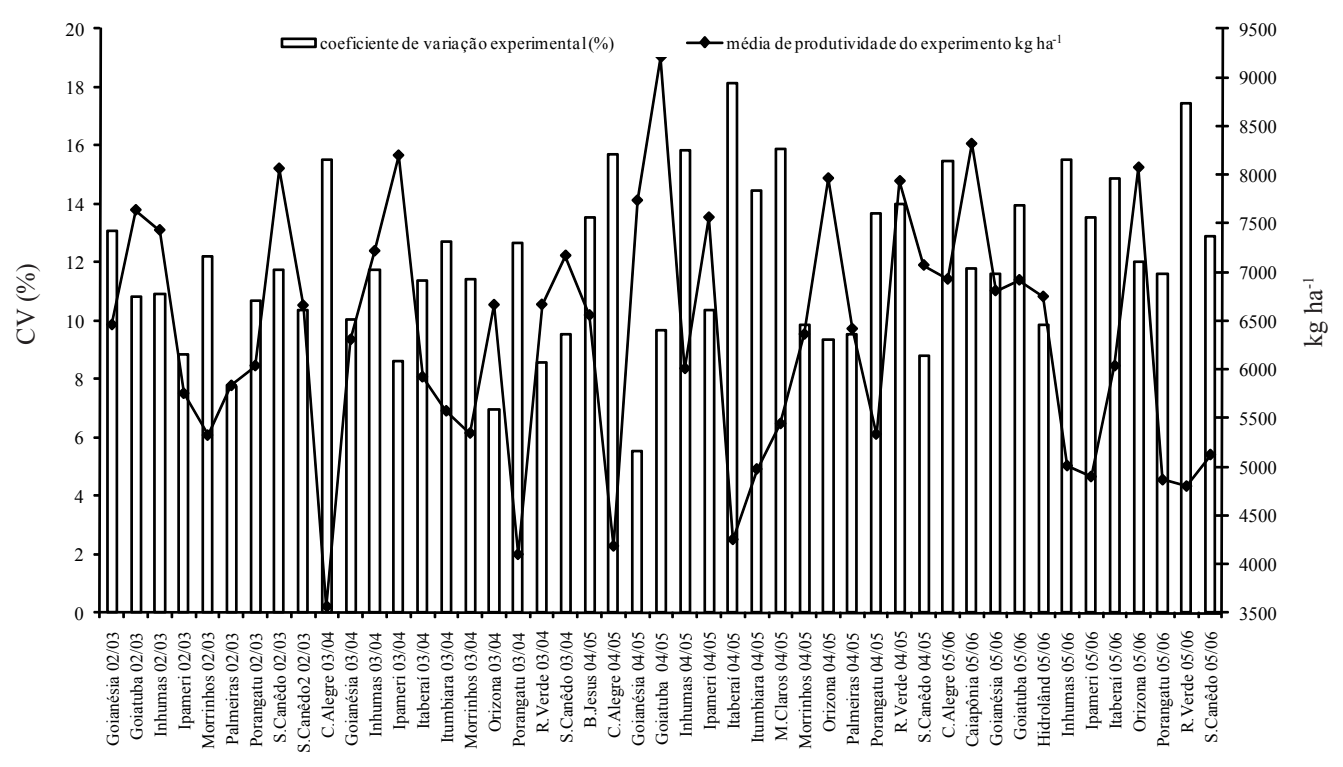

Figura 1. Coeficientes de variação experimental (\%) e médias de produtividade $\left(\mathrm{kg} \mathrm{ha}^{-1}\right)$ dos experimentos de avaliação de variedades de milho, em Goiás (safras 2002/2003 a 2005/2006). 
Tabela 4. Matriz de médias de produtividade de grãos $\left(\mathrm{kg} \mathrm{ha}^{-1}\right)$, para genótipos e ambientes, estimadas pelo modelo AMMI 1 , a partir de ensaios varietais de milho conduzidos em Goiás (safra 2002/2003).

\begin{tabular}{lccccccccc}
\hline Safra 2002/03 & Goianésia & Goiatuba & Inhumas & Ipameri & Morrinhos & Palmeiras & Porangatu & S. Canêdo & S.Canêdo2 \\
\hline Airã & 6684 & 7572 & 7474 & 5710 & 5388 & 6241 & 6272 & 8098 & 6514 \\
AL25 & 6852 & 7866 & 7747 & 6008 & 5657 & 6321 & 6435 & 8356 & 6895 \\
AL30 & 6581 & 7755 & 7608 & 5901 & 5515 & 5940 & 6156 & 8198 & 6893 \\
AL34 & 6734 & 7697 & 7587 & 5837 & 5499 & 6238 & 6318 & 8202 & 6692 \\
ALBandeirante & 7089 & 7571 & 7544 & 5698 & 5468 & 6926 & 6695 & 8216 & 6234 \\
AREgo18 & 5763 & 7381 & 7157 & 5539 & 5053 & 4815 & 5319 & 7695 & 6825 \\
BRS473 & 6279 & 7199 & 7096 & 5338 & 5009 & 5814 & 5866 & 7717 & 6164 \\
Emcapa202 & 6068 & 7566 & 7363 & 5721 & 5262 & 5203 & 5629 & 7916 & 6929 \\
IAC8333 & 6908 & 7885 & 7772 & 6025 & 5683 & 6404 & 6493 & 8386 & 6888 \\
IPR114 & 6366 & 7319 & 7210 & 5459 & 5122 & 5877 & 5951 & 7827 & 6306 \\
PC9703 & 6362 & 7722 & 7543 & 5873 & 5445 & 5593 & 5929 & 8111 & 6988 \\
Samambóleo & 6369 & 7581 & 7428 & 5728 & 5333 & 5703 & 5943 & 8014 & 6746 \\
Saracura & 6370 & 7486 & 7349 & 5630 & 5257 & 5769 & 5948 & 7946 & 6585 \\
SHS3030 & 6772 & 7634 & 7541 & 5771 & 5455 & 6347 & 6362 & 8168 & 6558 \\
Sol da manhã & 5687 & 7251 & 7037 & 5408 & 4934 & 4776 & 5245 & 7582 & 6659 \\
\hline
\end{tabular}

Tabela 5. Matriz de médias de produtividade de grãos $\left(\mathrm{kg} \mathrm{ha}^{-1}\right)$, para genótipos e ambientes, estimadas pelo modelo AMMI1, a partir de ensaios varietais de milho conduzidos em Goiás (safra 2003/2004).

\begin{tabular}{lccccccccccc}
\hline Safra 2003/04 & C. Alegre & Goianésia & Inhumas & Ipameri & Itaberaí & Itumbiara & Morrinhos & Orizona & Porangatu & Rio Verde & S. Canêdo \\
\hline AL25 & 3799 & 6544 & 7443 & 8414 & 6173 & 5810 & 5549 & 6858 & 4325 & 6890 & 7313 \\
AL30 & 3950 & 6680 & 7676 & 8654 & 6262 & 5852 & 5832 & 7143 & 4503 & 7108 & 7836 \\
AL34 & 3934 & 6664 & 7656 & 8633 & 6249 & 5841 & 5809 & 7121 & 4486 & 7088 & 7801 \\
ALBandeirante & 4039 & 6754 & 7841 & 8826 & 6292 & 5839 & 6044 & 7357 & 4618 & 7259 & 8271 \\
ALBianco & 3449 & 6179 & 7171 & 8149 & 5763 & 5355 & 5325 & 6636 & 4001 & 6604 & 7318 \\
Alvorada & 3495 & 6236 & 7159 & 8132 & 5853 & 5478 & 5278 & 6588 & 4028 & 6603 & 7103 \\
Assum Preto & 2747 & 5589 & 5874 & 6800 & 5516 & 5448 & 3664 & 4964 & 3099 & 5416 & 3923 \\
BR106 & 3295 & 6039 & 6947 & 7918 & 5663 & 5296 & 5057 & 6367 & 3823 & 6392 & 6845 \\
BRS1010 & 4357 & 7046 & 8297 & 9294 & 6504 & 5972 & 6585 & 7900 & 4982 & 7690 & 9214 \\
BRS4150 & 3287 & 6035 & 6912 & 7882 & 5675 & 5323 & 5007 & 6316 & 3806 & 6362 & 6718 \\
BRS473 & 3286 & 6051 & 6821 & 7783 & 5743 & 5442 & 4860 & 6168 & 3775 & 6288 & 6308 \\
BRSCaimbé & 3945 & 6672 & 7688 & 8668 & 6244 & 5825 & 5855 & 7167 & 4505 & 7117 & 7908 \\
Cativerde1 & 3432 & 6162 & 7158 & 8137 & 5743 & 5333 & 5315 & 6627 & 3986 & 6590 & 7321 \\
Cativerde2 & 3559 & 6255 & 7466 & 8460 & 5733 & 5220 & 5733 & 7047 & 4173 & 6864 & 8263 \\
Emcapa202 & 3481 & 6259 & 6946 & 7902 & 5991 & 5730 & 4943 & 6250 & 3947 & 6426 & 6189 \\
Emgopa501 & 3265 & 6000 & 6960 & 7936 & 5600 & 5208 & 5098 & 6408 & 3808 & 6398 & 7012 \\
Ipiranga & 3571 & 6296 & 7322 & 8302 & 5864 & 5440 & 5494 & 6805 & 4133 & 6749 & 7570 \\
IPR114 & 3598 & 6364 & 7130 & 8091 & 6058 & 5759 & 5167 & 6474 & 4086 & 6597 & 6604 \\
PC9902 & 3500 & 6239 & 7175 & 8148 & 5850 & 5469 & 5300 & 6610 & 4036 & 6616 & 7155 \\
PC9903 & 3381 & 6110 & 7114 & 8093 & 5688 & 5274 & 5274 & 6586 & 3937 & 6545 & 7297 \\
Piratininga & 3812 & 6519 & 7658 & 8647 & 6032 & 5553 & 5889 & 7202 & 4406 & 7068 & 8244 \\
SHS3031 & 3623 & 6363 & 7292 & 8266 & 5977 & 5600 & 5414 & 6724 & 4157 & 6735 & 7254 \\
Sol da manhã & 3098 & 5885 & 6517 & 7468 & 5643 & 5408 & 4486 & 5791 & 3548 & 6005 & 5596 \\
\hline
\end{tabular}

(Figura 2b). Apenas em Itumbiara, a variedade não liderou a classificação em produtividade, mas, ainda assim, ficou apenas $13 \mathrm{~kg} \mathrm{ha}^{-1}$ abaixo da média do genótipo mais produtivo (excluindo-se BRS1010), a variedade AL30 (Tabela 5). Esta superioridade, no seu comportamento produtivo, impediu, portanto, a formação de zonas específicas naquele ano agrí- cola, implicando na eleição desta variedade como a mais adaptada a todos os locais avaliados nessa safra: Itumbiara, Itaberaí, Goianésia, Campo Alegre, Porangatu, Rio Verde, Inhumas, Ipameri, Orizona, Morrinhos e Senador Canêdo.

Vale ressaltar que a estratificação resultante desta abordagem pode decorrer, principalmente, do 
(a) Safra 2002/03
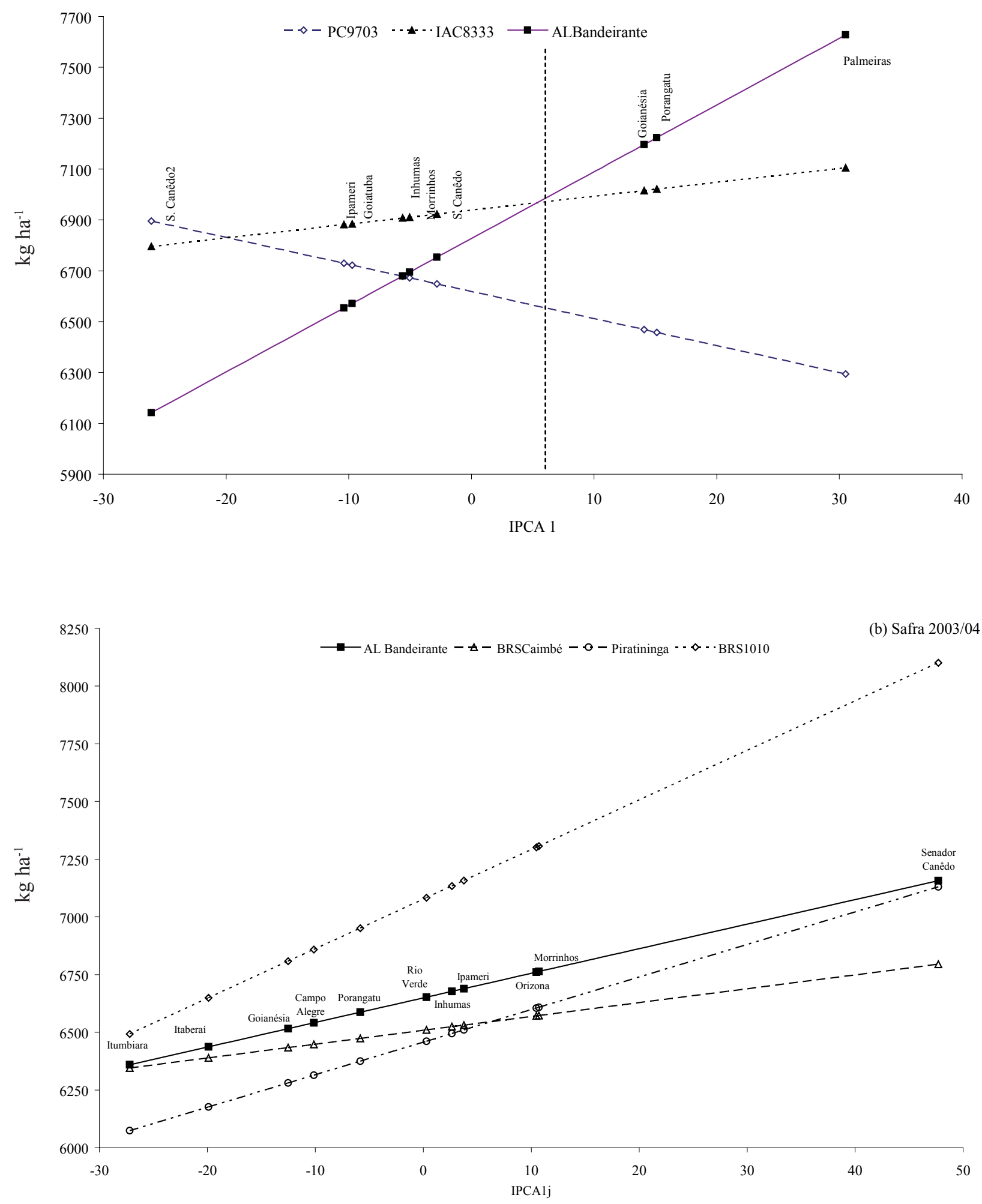

Figura 2. Respostas genotípicas de produtividade dos genótipos vencedores, em 2002/2003 (a) e 2003/2004 (b), em função dos escores ambientais estimados pelo modelo AMMI1 (IPCA $1_{\mathrm{j}}$ ). Cada genótipo vencedor (potencial cultivar de adaptação específica) determina um estrato de ambientes. A linha vertical pontilhada identifica a transição entre dois estratos e corresponde ao cruzamento entre as linhas de regressão dos genótipos vencedores. 
comportamento altamente adaptado do genótipo vencedor e não, necessariamente, das similaridades edafoclimáticas entre os locais agrupados. De qualquer modo, no que tange à recomendação da variedade ALBandeirante, a confiabilidade da estratificação não fica comprometida. Neste sentido, deve-se informar que esta abordagem metodológica comporta, também, a exclusão de genótipos vencedores absolutos, buscando sempre alguma subdivisão da população de ambientes. No presente caso, entretanto, esta estratégia não foi adotada, pois implicaria na separação de locais consistentemente reunidos nos demais anos (ex.: Senador Canêdo, Inhumas e Ipameri) e, também, nesta safra.

Na safra 2004/2005, os genótipos Cerrado, Orion e AL34 foram os vencedores principais (Tabela 6 e Figura 3a). Entretanto, este último genótipo foi excluído pelo critério dos vencedores menores (vitória apenas em Goiatuba). Tal exclusão implica em perda ínfima no local Goiatuba, estimada em, apenas, $25 \mathrm{~kg} \mathrm{ha}^{-1}$, ao se adotar a cultivar Orion como genótipo vencedor neste local. Esta substituição culminou na formação de dois estratos ambientais naquela safra, o que resulta em maior praticidade operacional para a recomendação e liberação de cultivares. Dessa forma, o comportamento da cultivar
Cerrado levou à formação de um primeiro estrato, reunindo Orizona, Porangatu, Rio Verde, Ipameri, Goianésia, Morrinhos, Palmeiras, Senador Canêdo, Campo Alegre, Itaberaí e Inhumas (Figura 3a). O outro estrato, determinado pelas vitórias do genótipo Orion, ficou constituído por Bom Jesus, Itumbiara, Montes Claros e Goiatuba.

Na safra 2005/2006, a escolha dos genótipos vencedores recaiu sobre os materiais AL200205, ALBandeirante, Piratininga e IPR114 (Tabela 7 e Figura 3b). Dentre estes, o primeiro e o último, que venceram em um só local cada um (Goiatuba e Campo Alegre, respectivamente), foram excluídos do processo, pelo critério de vencedores menores. Em Goiatuba, a substituição de AL200205 pelo genótipo vencedor seguinte, a variedade Piratininga, implicou em perda de produtividade insignificante $\left(5 \mathrm{~kg} \mathrm{ha}^{-1}\right)$. No caso de Campo Alegre, esta exclusão implicaria na eleição de outro vencedor menor, o genótipo IPV 7352, que, pelo mesmo motivo, também foi excluído. A perda máxima de produtividade para o estrato, associada à substituição dos dois primeiros vencedores neste local pela variedade ALBandeirante, o vencedor seguinte, foi pequena, não ultrapassando $87 \mathrm{~kg} \mathrm{ha}^{-1}$. Assim, a estratificação, nesta safra, ficou definida pela variedade Piratininga,

Tabela 6. Matriz de médias de produtividade de grãos $\left(\mathrm{kg} \mathrm{ha}^{-1}\right)$, para genótipos e ambientes, estimadas pelo modelo AMMI1, a partir de ensaios varietais de milho conduzidos em Goiás (safra 2004/2005).

\begin{tabular}{|c|c|c|c|c|c|c|c|c|c|c|c|c|c|c|c|}
\hline Safra 2004/05 & B.Jesus & C.Alegre & Goianésia & Goiatuba & Inhumas & Ipameri & Itaberaí & Itumbiara & M. Claros & Morrinhos & Orizona & Palmeiras & Porangatu & Rio Verde & S. Canêdo \\
\hline AL25 & 6492 & 4149 & 7751 & 8877 & 5941 & 7593 & 4212 & 4870 & 5277 & 6365 & 8041 & 6413 & 5407 & 8004 & 7060 \\
\hline AL30 & 6751 & 4344 & 7865 & 9519 & 6183 & 7682 & 4413 & 5135 & 5661 & 6497 & 8059 & 6555 & 5434 & 8035 & 7213 \\
\hline AL34 & 6931 & 4418 & 7802 & 10341 & 6336 & 7578 & 4499 & 5325 & 6052 & 6465 & 7837 & 6541 & 5226 & 7836 & 7218 \\
\hline ALBandeirante & 6912 & 4475 & 7958 & 9859 & 6336 & 7764 & 4548 & 5298 & 5880 & 6599 & 8108 & 6662 & 5487 & 8091 & 7325 \\
\hline ALBianco & 6642 & 4171 & 7610 & 9797 & 6057 & 7402 & 4247 & 5032 & 5679 & 6260 & 7708 & 6329 & 5091 & 7698 & 6998 \\
\hline Alvorada & 6719 & 4395 & 8021 & 8987 & 6172 & 7871 & 4455 & 5095 & 5465 & 6630 & 8340 & 6675 & 5704 & 8299 & 7319 \\
\hline Assum Preto & 5723 & 3377 & 6975 & 8125 & 5170 & 6816 & 3439 & 4101 & 4513 & 5590 & 7260 & 5638 & 4627 & 7224 & 6286 \\
\hline BR106 & 6465 & 4140 & 7765 & 8739 & 5918 & 7615 & 4200 & 4841 & 5213 & 6375 & 8082 & 6419 & 5447 & 8042 & 7063 \\
\hline BRS2020 & 6886 & 4445 & 7921 & 9861 & 6309 & 7725 & 4518 & 5273 & 5864 & 6563 & 8064 & 6628 & 5443 & 8048 & 7292 \\
\hline BRS4150 & 6242 & 3922 & 7555 & 8482 & 5696 & 7407 & 3982 & 4618 & 4979 & 6163 & 7881 & 6206 & 5244 & 7839 & 6849 \\
\hline BRS473 & 6308 & 3902 & 7422 & 9077 & 5740 & 7239 & 3971 & 4692 & 5219 & 6054 & 7616 & 6113 & 4991 & 7593 & 6771 \\
\hline Cativerde2 & 6697 & 4300 & 7833 & 9405 & 6131 & 7654 & 4368 & 5080 & 5587 & 6463 & 8042 & 6519 & 5416 & 8017 & 7176 \\
\hline Cerrado & 7048 & 4683 & 8257 & 9564 & 6491 & 8091 & 4748 & 5428 & 5875 & 6878 & 8514 & 6929 & 5884 & 8482 & 7580 \\
\hline Emcapa202 & 6647 & 4226 & 7728 & 9503 & 6075 & 7539 & 4297 & 5032 & 5586 & 6364 & 7900 & 6425 & 5277 & 7880 & 7086 \\
\hline Emgopa501 & 6503 & 4086 & 7593 & 9333 & 5932 & 7407 & 4156 & 4888 & 5433 & 6229 & 7772 & 6289 & 5148 & 7751 & 6949 \\
\hline IAC8333 & 6739 & 4348 & 7888 & 9415 & 6175 & 7712 & 4416 & 5122 & 5619 & 6517 & 8106 & 6572 & 5479 & 8079 & 7228 \\
\hline Ipiranga & 6673 & 4274 & 7805 & 9391 & 6107 & 7626 & 4343 & 5056 & 5567 & 6436 & 8012 & 6492 & 5386 & 7987 & 7149 \\
\hline Orion & 7066 & 4580 & 7998 & 10316 & 6477 & 7784 & 4658 & 5458 & 6134 & 6653 & 8073 & 6725 & 5458 & 8066 & 7397 \\
\hline PC201 & 6734 & 4340 & 7876 & 9428 & 6169 & 7699 & 4408 & 5117 & 5620 & 6505 & 8089 & 6561 & 5462 & 8063 & 7217 \\
\hline PC202 & 6648 & 4295 & 7884 & 9093 & 6094 & 7723 & 4359 & 5027 & 5452 & 6502 & 8159 & 6551 & 5527 & 8124 & 7200 \\
\hline PC203 & 6637 & 4248 & 7791 & 9298 & 6073 & 7615 & 4315 & 5019 & 5512 & 6418 & 8012 & 6474 & 5384 & 7985 & 7129 \\
\hline РС9703 & 6484 & 4185 & 7844 & 8599 & 5944 & 7704 & 4243 & 4858 & 5180 & 6446 & 8201 & 6486 & 5562 & 8155 & 7126 \\
\hline Piratininga & 7029 & 4543 & 7961 & 10279 & 6440 & 7747 & 4621 & 5420 & 6097 & 6616 & 8036 & 6688 & 5421 & 8029 & 7360 \\
\hline Sambaia & 6355 & 4063 & 7731 & 8429 & 5817 & 7594 & 4120 & 4728 & 5038 & 6331 & 8098 & 6370 & 5458 & 8050 & 7008 \\
\hline Saracura & 6018 & 3638 & 7194 & 8622 & 5457 & 7022 & 3705 & 4399 & 4874 & 5818 & 7429 & 5872 & 4800 & 7400 & 6526 \\
\hline S.Manhã & 5781 & 3488 & 7156 & 7857 & 5242 & 7018 & 3545 & 4154 & 4464 & 5756 & 7522 & 5795 & 4882 & 7474 & 6433 \\
\hline UFVM100 & 6649 & 4262 & 7807 & 9302 & 6086 & 7632 & 4329 & 5032 & 5522 & 6434 & 8030 & 6489 & 5403 & 8003 & 7144 \\
\hline UFVM200 & 6211 & 3917 & 7582 & 8297 & 5672 & 7444 & 3974 & 4584 & 4897 & 6183 & 7946 & 6222 & 5307 & 7899 & 6860 \\
\hline
\end{tabular}



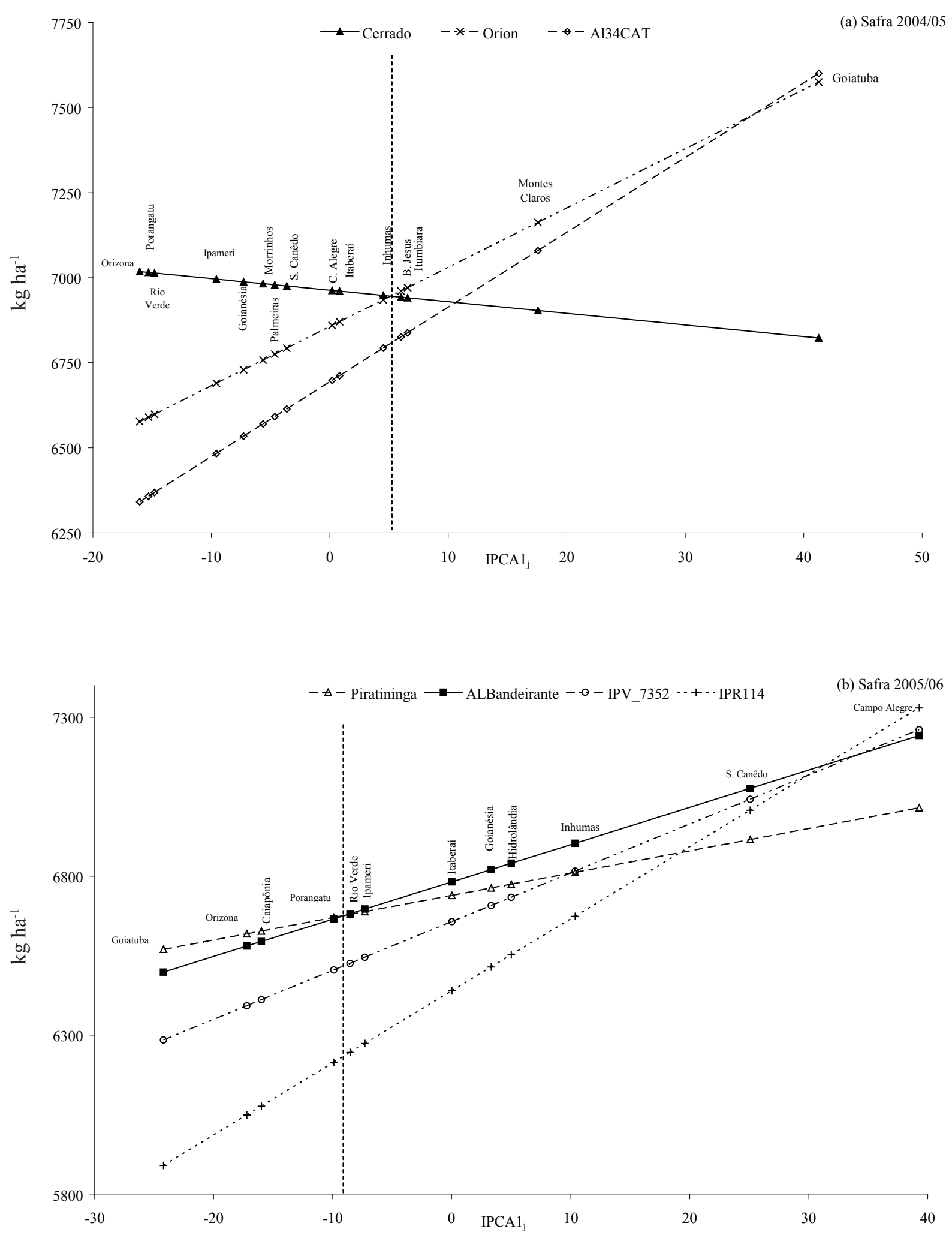

Figura 3. Respostas genotípicas de produtividade dos genótipos vencedores, em 2004/2005(a) e 2005/2006(b), em função dos escores ambientais estimados pelo modelo AMMI 1 (IPCA $l_{\mathrm{j}}$ ). Cada genótipo vencedor (potencial cultivar de adaptação específica) determina um estrato de ambientes. As linhas verticais pontilhadas identificam a transição entre dois estratos e correspondem ao cruzamento entre as linhas de regressão dos genótipos vencedores. 
Tabela 7. Matriz de médias de produtividade de grãos $\left(\mathrm{kg} \mathrm{ha}^{-1}\right)$, para genótipos e ambientes, estimadas pelo modelo AMMI 1 , a partir de ensaios varietais de milho conduzidos em Goiás (safra 2005/2006).

\begin{tabular}{|c|c|c|c|c|c|c|c|c|c|c|c|c|}
\hline Safra 2005/06 & C. Alegre & Caiapônia & Goianésia & Goiatuba & Hidrolândia & Inhumas & Ipameri & Itaberaí & Orizona & Porangatu & Rio Verde & S. Canêdo \\
\hline AL200205 & 7153 & 8663 & 7112 & 7283 & 7049 & 5299 & 5226 & 6348 & 8457 & 5170 & 5120 & 5381 \\
\hline AL34 & 7602 & 8371 & 7079 & 6880 & 7038 & 5361 & 5050 & 6271 & 8149 & 4959 & 4927 & 5639 \\
\hline ALBandeirante & 7960 & 8701 & 7419 & 7207 & 7379 & 5704 & 5385 & 6609 & 8478 & 5293 & 5261 & 5990 \\
\hline ALBianco & 7120 & 8367 & 6907 & 6947 & 6852 & 5129 & 4971 & 6128 & 8155 & 4902 & 4858 & 5280 \\
\hline Alvorada & 6749 & 8365 & 6777 & 7001 & 6710 & 4951 & 4911 & 6020 & 8162 & 4860 & 4807 & 5004 \\
\hline Assum Preto & 5514 & 7769 & 5957 & 6499 & 5871 & 4050 & 4214 & 5238 & 7579 & 4193 & 4125 & 3933 \\
\hline BR106 & 7427 & 8505 & 7105 & 7061 & 7055 & 5347 & 5136 & 6316 & 8290 & 5060 & 5020 & 5544 \\
\hline BRS4150 & 5206 & 7326 & 5562 & 6036 & 5480 & 3671 & 3793 & 4834 & 7133 & 3765 & 3700 & 3591 \\
\hline BRS473 & 4643 & 8139 & 5894 & 7054 & 5770 & 3828 & 4389 & 5249 & 7977 & 4427 & 4328 & 3381 \\
\hline Ipiranga & 7605 & 8526 & 7181 & 7058 & 7135 & 5443 & 5182 & 6382 & 8307 & 5098 & 5062 & 5682 \\
\hline IPR114 & 8047 & 8183 & 7112 & 6598 & 7090 & 5475 & 4962 & 6266 & 7947 & 4841 & 4825 & 5922 \\
\hline IPV7352 & 7978 & 8518 & 7305 & 6993 & 7272 & 5617 & 5233 & 6484 & 8290 & 5131 & 5105 & 5957 \\
\hline PC0201 & 7455 & 8510 & 7117 & 7062 & 7068 & 5363 & 5144 & 6327 & 8294 & 5066 & 5027 & 5566 \\
\hline Piratininga & 7733 & 8734 & 7361 & 7278 & 7313 & 5613 & 5377 & 6567 & 8517 & 5297 & 5259 & 5830 \\
\hline Samambaia & 6886 & 8187 & 6709 & 6776 & 6652 & 4923 & 4783 & 5933 & 7977 & 4717 & 4672 & 5061 \\
\hline Sol da manhã & 6932 & 7957 & 6575 & 6504 & 6526 & 4824 & 4596 & 5782 & 7740 & 4517 & 4478 & 5035 \\
\hline UFVM100 & 6948 & 8496 & 6932 & 7122 & 6867 & 5114 & 5053 & 6170 & 8291 & 4999 & 4947 & 5186 \\
\hline UFVM200 & 5726 & 8376 & 6426 & 7165 & 6328 & 4469 & 4759 & 5731 & 8195 & 4757 & 4679 & 4247 \\
\hline
\end{tabular}

vencedora nos locais Goiatuba, Orizona, Caiapônia e Porangatu, constituindo-se um primeiro estrato ambiental, e pela variedade ALBandeirante, que define outro estrato com maior número de locais, a saber, Rio Verde, Ipameri, Itaberaí, Goianésia, Hidrolândia, Inhumas, Senador Canêdo e Campo Alegre (Figura 3b).

Uma vantagem considerável da estratificação ambiental, segundo a abordagem de genótipos vencedores, sobretudo em associação à análise AMMI, é a informação integrada da recomendação de genótipos para cada estrato estabelecido (Pacheco et al. 2009). Assim, dispensam-se estudos adicionais sobre estabilidade e adaptabilidade fenotípica, haja vista não haver interação GxA cruzada dentro dos estratos. Logo, a indicação do genótipo mais adaptado à região, representada por um estrato ambiental, é imediata e incide, logicamente, sobre o seu genótipo vencedor.

No presente estudo, como parte dos genótipos foi substituída com o passar dos anos e outros tratavam-se de híbridos (ex.: Orion e IAC8333) ou de materiais pré-comerciais, como a variedade Cerrado, a recomendação de genótipos, segundo a adaptabilidade produtiva, foi centrada na identificação das variedades vencedoras na última safra avaliada. De qualquer modo, dos sete estratos ambentais constituídos ao longo das quatro safras, três foram estabelecidos com base no comportamento vencedor do genótipo ALBandeirante. Esta constatação evidencia a ampla adaptação desta variedade às condições de cultivo do milho no Estado de Goiás.
Considerando-se tão somente a última safra (2005/2006), esta recomendação se confirma, remetendo à indicação da variedade ALBandeirante, para o estrato destacado anteriormente, formado por Rio Verde, Ipameri, Itaberaí, Goianésia, Hidrolândia, Inhumas, Senador Canêdo e Campo Alegre de Goiás (Figura 3b). Ademais, como o local Morrinhos reuniu-se, por dois anos, ao agrupamento de locais relacionados a este estrato, a recomendação da variedade ALBandeirante, também para este local, parece parcimoniosa, ainda que este ambiente não tenha sido avaliado na safra 2005/2006. Já a variedade Piratininga é indicada para cultivo nos locais do outro estrato (Goiatuba, Orizona, Caiapônia e Porangatu), em razão de ter se mostrado a mais produtiva e, portanto, mais adaptada às condições ambientais representadas por este estrato (Figura 3b). Por outro lado, a extensão da recomendação de ALBandeirante, também para este estrato, não implicaria em perdas significativas de produtividade, isto é, representaria $71 \mathrm{~kg} \mathrm{ha}{ }^{-1}$, em Goiatuba; $39 \mathrm{~kg} \mathrm{ha}^{-1}$, em Orizona; $33 \mathrm{~kg} \mathrm{ha}^{-1}$, em Caiapônia; e apenas $4 \mathrm{~kg} \mathrm{ha}^{-1}$, em Porangatu (Tabela 7). Tais recomendações, contudo, devem levar em consideração, ainda, os custos e a disponibilidade de sementes de ambas as variedades.

Ao se comparar os estratos ambientais (megaambientes) formados ao longo das quatro safras avaliadas (Tabela 8), pôde-se constatar a formação de, pelo menos, dois agrupamentos estáveis, ao longo do período. No primeiro deles, os locais que se agruparam de maneira mais consistente foram Ipameri, 
Inhumas e Senador Canêdo, que se mantiveram reunidos em estratos ambientais comuns, nas quatro safras agrícolas. A este grupo se juntaram, ainda, por três anos, Morrinhos, nas safras 2002/2003, 2003/2004 e 2004/2005, e Itaberaí, Campo Alegre e Rio Verde, nas safras 2003/2004, 2004/2005 e 2005/2006. O outro grupo consistente de locais foi constituído por Porangatu e Orizona, que se agruparam em estratos ambientais comuns, em todas as safras nas quais foram avaliados.

Outros locais mostraram-se instáveis, ora agrupando-se a um dos estratos ambientais mais consistentes, ora ao outro destes estratos. Este é o caso, por exemplo, do local Goianésia, que se manteve reunido ao local Porangatu, nas três primeiras safras, mas não revelou a mesma similaridade no último ano (Tabela 8). Paradoxalmente, embora tenha se mostrado dissimilar do grupo constituído pelos locais Ipameri, Inhumas e Senador Canêdo, no primeiro ano (2002/2003), nos outros três anos avaliados, mantiveram-se agrupados. Tendência semelhante foi observada para a localidade Palmeiras, embora esta tenha sido avaliada em apenas duas safras. O local Goiatuba também revelou instabilidade, em relação aos dois estratos mais consistentes. Isto, provavelmente, deve-se ao fato de que, embora em um mesmo município, de uma safra para outra, os ensaios tiveram variação de altitude da ordem de
$300 \mathrm{~m}$. Esta hipótese pode ser reforçada pelo agrupamento deste local com Itumbiara e Bom Jesus, em 2004/2005, que são locais geograficamente próximos entre si e ao primeiro, e de altitudes médias relativamente menores. Sobre os demais locais (Senador Canêdo2, Montes Claros, Caiapônia e Hidrolândia), não se evidenciaram comportamentos regulares que justificassem quaisquer inferências acerca de suas tendências agroecológicas, também porque, neste estudo, estes foram avaliados em apenas um ano agrícola.

Conforme defendido por Pacheco (2004), pela estabilidade de alguns agrupamentos de locais, ao longo dos anos, mesmo sob a utilização de diferentes genótipos, é de se esperar que os estratos ambientais assim identificados tenham caráter preditivo. Isto significa que tais estratos podem ser utilizados, com relativa segurança, tanto para a recomendação de cultivares, com a eleição da mesma cultivar para os diferentes locais de cada estrato, quanto para a exclusão ou substituição de locais de teste por outros que permitam ampliar e melhorar a avaliação da interação GxA.

Em relação à escolha de locais prioritários para testes genotípicos, no caso do estrato ambiental formado por Ipameri, Inhumas e Senador Canêdo, consistente por quatro anos (incluindo-se ou não os locais Morrinhos, Itaberaí, Campo Alegre e Rio

Tabela 8. Estratos ambientais ${ }^{1}$ para avaliação e recomendação de variedades de milho no Estado de Goiás, resultantes da aplicação da abordagem de genótipos vencedores, associada à análise AMMI, em diferentes anos agrícolas.

\begin{tabular}{|c|c|c|c|c|c|c|c|}
\hline \multicolumn{2}{|c|}{ Safra 2002/2003 } & \multicolumn{2}{|c|}{ Safra 2003/2004 } & \multicolumn{2}{|c|}{ Safra 2004/2005 } & \multicolumn{2}{|c|}{ Safra 2005/2006 } \\
\hline Estrato & Locais & Estrato & Locais & Estrato & Locais & Estrato & Locais \\
\hline 1 & Senador Canêdo 2 & 1 & Itumbiara & 1 & Orizona & 1 & Goiatuba \\
\hline 1 & Ipameri & 1 & Itaberaí $^{*}$ & 1 & Porangatu & 1 & Orizona \\
\hline 1 & Goiatuba & 1 & Goianésia & 1 & Rio Verde* & 1 & Caiapônia \\
\hline 1 & Inhumas & 1 & Campo Alegre* & 1 & Ipameri & 1 & Porangatu \\
\hline 1 & Morrinhos* & 1 & Porangatu & 1 & Goianésia & 2 & Rio Verde* \\
\hline 1 & Senador Canêdo & 1 & Rio Verde* & 1 & Morrinhos ${ }^{*}$ & 2 & Ipameri \\
\hline 2 & Goianésia & 1 & Inhumas & 1 & Palmeiras & 2 & Itaberai ${ }^{*}$ \\
\hline 2 & Porangatu & 1 & Ipameri & 1 & Senador Canêdo & 2 & Goianésia \\
\hline 2 & Palmeiras & 1 & Morrinhos* & 1 & Campo Alegre* & 2 & Hidrolândia \\
\hline- & - & 1 & Orizona & 1 & Itaberaí $^{*}$ & 2 & Inhumas \\
\hline- & - & 1 & Senador Canêdo & 1 & Inhumas & 2 & Senador Canêdo \\
\hline- & - & - & - & 2 & Bom Jesus & 2 & Campo Alegre* \\
\hline- & - & - & - & 2 & Itumbiara & - & - \\
\hline- & - & - & - & 2 & Montes Claros & - & - \\
\hline- & - & - & - & 2 & Goiatuba & - & - \\
\hline
\end{tabular}

${ }^{1}$ Estratos consistentes ou estáveis, ao longo de quatro anos, dentro da safra, têm nomes de locais destacados em negrito. Estratos consistentes, por três anos, são destacados em itálico.

* Os locais Morrinhos, Itaberaí, Campo Alegre e Rio Verde podem ser agrupados ao estrato ambiental destacado em negrito, reduzindo-se a consistência da estratificação para três anos. 
Verde, que a eles se uniram em três das quatro safras), poder-se-ia manter apenas o local Senador Canêdo. Isto, porque, além de localizar-se em região central do Estado de Goiás, o local já possui estação experimental (Seagro-GO) relativamente bem estruturada. No estrato formado por Porangatu e Orizona, poder-se-ia manter apenas Porangatu, como local de teste, pois, além de situar-se mais ao norte do Estado, também possui uma estação experimental da Seagro-GO. Este tipo de providência representaria redução de $16,7 \%$ nos locais de teste (de 18 para 15 locais), ou até 38,9\% (de 18 para 11 locais), no caso de se incluir os outros quatro locais no primeiro dos estratos consistentes, com impactos diretos no custo de implantação e condução da rede de ensaios. Com isto, seria possível, ainda, a substituição de locais participantes da rede por outros que melhor representariam a região alvo da recomendação de variedades, de modo a aumentar a eficiência de avaliação da interação GxA, no âmbito do programa de melhoramento.

\section{CONCLUSÕES}

1. A avaliação e a recomendação de variedades de milho para o Estado de Goiás podem ser feitas com base em dois principais estratos de ambientes: E1 (Ipameri, Inhumas e Senador Canêdo), consistente ao longo de quatro safras, ao qual se podem agregar os locais Morrinhos, Itaberaí, Campo Alegre e Rio Verde, reduzindo-se esta consistência para três anos; e E2 (Porangatu e Orizona), consistente ao longo de três anos agrícolas.

2. A variedade ALBandeirante apresenta alto potencial produtivo e ampla adaptabilidade aos diferentes estratos ambientais identificados na região.

3. O número de pontos para a instalação e condução da rede de ensaios de avaliação de variedades de milho, em Goiás, pode ser reduzido em 16,7\%, sem prejuízo relevante sobre os efeitos da interação deste tipo de genótipo com os ambientes.

\section{REFERÊNCIAS}

BALESTRE, M. et al. Yield stability and adaptabilty of maize hybrids based on GGE biplot analysis characteristics. Crop Science, Madison, v. 9, n. 4, p. 219-228, 2009.

BRASIL. Portaria n 294, de 14 de outubro de 1998. Estabelece os critérios mínimos a serem observados nos ensaios para determinação do Valor de Cultivo e Uso - VCU de cultivares de algodão, arroz, batata, feijão, milho, soja, sorgo e trigo e os respectivos formulários de solicitação de inscrição de cultivares no Registro Nacional de Cultivares - RNC. Diário Oficial da República Federativa do Brasil, Brasília, DF, 16 out. 1998. Disponível em: <http://extranet.agricultura.gov.br/ sislegis-consulta/consultarLegislacao.do?operacao=visua lizar\&id=15013>. Acesso em: 19 fev. 2010.

DUARTE, J. B.; VENCOVSKY, R. Interação genótipos $x$ ambientes: uma introdução à análise "AMMI". Ribeirão Preto: Sociedade Brasileira de Genética, 1999. (Monografias, 9).

EBDON, J. S; GAUCH, H. G. Additive main effect and multiplicative interaction analysis of national turfgrass performance trials: II. Cultivar recommendations. Crop Science, Madison, v. 42, n. 2, p. 497-506, 2002.

FELIPE, C. R. de P. Métodos de predição e estimação de valor genotípico e estratificação ambiental para avaliação e recomendação de cultivares. 2008. 113 f. Tese (Doutorado em Produção Vegetal)-Escola de Agronomia e Engenharia de Alimentos, Universidade Federal de Goiás, Goiânia, 2008.

GAUCH, H. G. Documentation for AMMIWINS. 1996. Disponnível em: <http://microcomputerpower.com/ ammiwins.html>. Acesso em: 02 fev. 2004.

GAUCH, H. G. Statistical analysis of regional yield trials: AMMI analysis of factorial designs. New York: Elsevier, 1992.

GAUCH, H. G. Statistical analysis of yield trials by AMMI and GGE. Crop Science, Madison, v. 46, n. 4, p. 14881500, 2006.

GAUCH, H. G.; ZOBEL, R. W. AMMI analysis of yield trials. In: KANG, M.S.; GAUCH, H. G. (Eds.). Genotype by enviroment interaction. Boca Raton: CRC Press, 1996. p. 85-122.

GAUCH, H. G.; ZOBEL, R. W. Identifying megaenvironments and targeting genotypes. Crop Science, Madison, v. 37, n. 2, p. 311-326, 1997.

GAUCH, H. G.; PIEPHO, H. P.; ANNICCHIARICO, P. Statistical analysis of yield trials by AMMI and GGE: further considerations. Crop Science, Madison, v. 48, n. 3 , p. 866-889, 2008.

MARANHA, F. G. C. B. Estratificação ambiental para avaliação de genótipos de algodoeiro no Estado do Mato Grosso. 2005. 63 f. Tese (Doutorado em Agronomia)Escola Superior de Agronomia Luiz de Queiroz, Universidade de São Paulo, Piracicaba, 2005.

MIRANDA, E. E. de; COUTINHO, A. C. (Coords.). Brasil visto do espaço. Campinas: Embrapa Monitoramento por Satélite, 2004. Disponível em: <http://www.cdbrasil. cnpm.embrapa.br>. Acesso em: 01 dez. 2004. 
MIRANDA, G. V. M. et al. Multivariate analyses of genotype $\mathrm{x}$ environment interaction of popcorn. Pesquisa Agropecuária Brasileira, Brasília, DF, v. 44, n. 1, p. 4550, 2009.

PACHECO, R. M. Estratificação de ambientes em Cerrados do Brasil Central para fins de seleção e recomendação de cultivares de soja. 2004. 170 f. Tese (Doutorado em Agronomia)-Escola de Agronomia e Engenharia de Alimentos, Universidade Federal de Goiás, Goiânia, 2004.

PACHECO, R. M. et al. Key locations for soybean genotype assessment in Central Brazil. Pesquisa Agropecuária Brasileira, Brasília, DF, v. 44, n. 5, p. 478-486, 2009.

PIMENTEL GOMES, F. Curso de estatística experimental. 8. ed. São Paulo: Nobel, 1990.
SAS INSTITUTE. SAS/STAT software: changes and enhancements through release 9.1. Cary: SAS Institute Inc., 2002.

VENCOVSKY, R. ; BARRIGA, P. Genética biométrica no fitomelhoramento. Ribeirão Preto: Sociedade Brasileira de Genética, 1992.

YAN, W.; TINKER, N. A. An integrated biplot analysis system for displaying, interpreting, and exploring genotype x environment interaction. Crop Science, Madison, v. 45, n. 3, p. 1004-1016, 2005.

YAN, W. et al. GGE biplot vs. AMMI analysis of genotypeby-environment data. Crop Science, Madison, v. 47, n. 2, p. 643-655, 2007. 